\title{
USING VORTEX TUBE FOR DECREASING LOSSES OF NATURAL GAS IN ENGINEERING SYSTEMS OF GAS SUPPLY
}

\author{
${ }^{1}$ Olena SAVCHENKO, ${ }^{2}$ Vasyl ZHELYKH, ${ }^{3}$ Yuriy YURKEVYCH \\ ${ }^{4}$ Stepan SHAPOVAL, ${ }^{5}$ Khrystyna KOZAK \\ 1,2,3,4,5 Department Heat, Gas Supply and Ventilation, Institute of Building and Environmental \\ Engineering, Lviv Polytechnic National University, Stepan Bandera str, 12, Lviv-13, Ukraine \\ e-mail: ${ }^{1}$ olena.o.savchenko@lpnu.ua, ${ }^{2}$ vasyl.m.zhelykh@1pnu.ua, ${ }^{3}$ yurii.s.yurkevych@lpnu.ua \\ ${ }^{4}$ stepan.p.shapoval@lpnu.ua, ${ }^{5}$ khrystyna.r.kozak@lpnu.ua
}

Received 2 February 2018; accepted 4 May 2018

\begin{abstract}
In this paper the method of reducing production and technological losses of natural gas in engineering systems of gas supply is considered. The reduction of the production and technological losses occurs at the gas distribution station when the natural gas heater is replaced by the vortex pipe. The heating of natural gas at the gas distribution stations is carried out to eliminate the icing of the gas pressure regulators during the throttling process. The main factors that influence the heating degree of gas in the vortex tube are determined. A study was conducted to determine the optimal dimensions of the vortex tube. It has been established that the presence of a vortex tube at gas distribution stations with a throughput of up to $2500 \mathrm{~m}^{3} /$ hour can reduce the production and technological losses of natural gas in engineering systems of gas supply.
\end{abstract}

Keywords: Engineering systems of gas supply, Gas distribution station, Vortex tube, Gas hydrates, Loss of natural gas

\section{Introduction}

Natural gas is the main energy source in Ukraine. In the structure of the total consumption of primary energy in Ukraine, its share is about $37 \%$. Each year, Ukraine consumes about 31 billion $\mathrm{m}^{3}$ of natural gas, of which it imports more than 11 billion $\mathrm{m}^{3}$. For energy independence of Ukraine it is necessary to reduce natural gas consumption. There are several ways to reduce natural gas consumption. For example, thermo-modernization of existing residential buildings [1], [2], [3] the use of alternative fuels, in particular biogas [4] and reduction of natural gas losses directly in engineering systems of gas supply. Annual losses of natural gas in engineering systems of gas 
supply are estimated at 2 billion $\mathrm{m}^{3}$. Natural gas losses in engineering systems of gas supply consist of production-technological losses and losses for own needs [5]. Production and technological losses of natural gas are the amount of gas that is lost during gas transportation by gas distribution and in-house networks, as well as during preventive maintenance and ongoing repairs. Own needs of the gas industry enterprises are gas losses that are not directly related to the technological process of gas transportation, for example, expenses for heating, hot water supply, ventilation of premises of enterprises of supply and sale of gas.

\section{Aim of work}

Determination the optimal sizes of the vortex pipe that is designed for the reduce production and technological losses of natural gas in engineering networks of gas supply is the purpose of the research.

\section{Analysis of existing studies}

One of the main consumers of natural gas for industrial and technological needs is the gas heaters at gas distribution stations. As it is known, heaters at gas distribution stations are used to heat natural gas in front of the gas pressure regulator. In the gas pressure regulator the pressure of the natural gas decreases from 7.5-3.0 $\mathrm{MPa}$ to 1.2 MPa. This process of irreversible transformation of work, used for changing the pressure to heat, is called throttling and is characterized by differential temperature of throttling effect $\alpha=(\partial T / \partial p)_{i}$, [6].

At the gas distribution station the differential temperature effect of throttling in the whole range of values of pressure and temperature is assumed to be equal to

$\alpha=-5.5{ }^{\circ} \mathrm{C} / \mathrm{MPa}$ that is when the gas pressure is lowered at gas distribution stations at $1 \mathrm{MPa}$, its temperature decreases by $5.5^{\circ} \mathrm{C}$. Consequently, when the natural gas is throttled, there is a decrease in not only its pressure, but also the temperature, and according to it the moisture content of the natural gas changes.

The presence of water vapor in natural gas can lead to the formation of gas hydrates, which are solid crystalline substances that look like snow or ice. They are characterized by a general formula $\mathrm{M} \cdot n \mathrm{H}_{2} \mathrm{O}$, where $\mathrm{M}$ is a molecule that forms hydrate at precisely defined values of pressure and temperature. The formation of gas hydrates can be formed during throttling natural gas in the pressure regulator at gas distribution stations. Gas hydrates are formed at the inlet of the gas pressure regulator during the contact of a wet gas with regulator's surface. It is cooled during gas throttling and condensation of water vapor in the regulator. Due to the formation of gas hydrates, the valve of the gas pressure regulator can be frozen to the saddle. A breakdown of the pressure regulator can lead to an emergency situation at the gas distribution station.

To prevent the formation of gas hydrates in the engineering systems of gas supply, the drying of natural gas, the injection of inhibitors into natural gas for depression of dew point and heating of natural gas are used, [7], [8], [9]. 
At gas distribution stations, natural gas heating is used to prevent the formation of gas hydrates in the pressure regulator. The aim of heating natural gas at the gas distribution station is to rise the gas temperature above the dew point at $5-7^{\circ} \mathrm{C}$. That is, the moisture content of the saturated gas should be higher than the moisture content of the gas entering at the gas distribution station. Depending on the productivity of the gas distribution station, different methods of heating natural gas are used. If the productivity of the gas distribution station is more than $70000 \mathrm{~m}^{3} /$ hour, it is expedient to use the local heating of the gas regulator housing, [10].

Various types of heat exchangers can be used for general heating of natural gas. They differ in the type of energy source (hot water, electric energy, water vapor) and the location of the heat exchange surfaces (heat exchangers 'pipe in a pipe', shell-and-tube heat exchanger). Their choice is related to the working conditions of the energy source.

The heat exchangers 'pipe in a pipe' is widespread for heating the gas. They are heat exchangers in the form of a system of sequentially connected coil pipes. Each coil pipe consists of two tubes: internal and external. The gas passes through the inner pipe, and in the inter-pipe space between the pipes circulating heat-transfer fluid (usually, hot water from the boiler). The limited losses of water pressure in heating system, the possibility of installing a heat exchanger in relation to the boiler on the required height are allowed to successfully use the natural circulation of water, which provides high heat transfer to gas. In this regard, there is no need for water pumps, that is, the forced circulation of hot water in the system. Application of heat exchangers 'pipe in a pipe' is expedient at a thermal power up to $17 \mathrm{~kW}$.

Shell-and-tube heat exchangers are used in the area of medium and large thermal power, which are formed by hot water, superheated and saturated steam. The apparatus consists of a cylindrical body, which has a tube board with a U-like beam of pipes. The apparatus on the side of the pipe board has a longitudinal partition that separates the section of the board with a U-like beam of pipes on the entrance and exit of the gas. Transverse partitions in the inter-pipe space allow maintaining the required flow velocity of the heat-transfer fluid in order to provide efficient heat transfer. U-like construction of beam pipes design provides temperature compensation for thermal elongation of beam pipes. With the heat exchange between the gas of high pressure and the heat-transfer fluid, the flow of gas passes through the tubes, and the flow of the heattransfer fluid - in the inter-pipe space. If the gas has medium or low pressure, then it is sent to the inter-pipe space, and water passes through the pipes. Usually high gas pressure allows maintaining high Reynolds numbers, which achieves satisfactory heattransfer coefficients for gas at low pressure losses. Forced circulation of the heattransfer fluid through the pump always contributes to the improvement of the heattransfer coefficient. In heat exchangers fed by the heat-transfer fluid with forced circulation, the necessary regulation of the process of heating the gas by the thermostatic regulator is provided. It affects the valve that is installed in the conduit for the heat-transfer fluid that enters the heat exchanger.

Fire heaters are monoblock installation consisting of a device for heating the intermediate heat-transfer fluid. The combustion chamber and two chimneys are located in the bottom of the cylindrical body and are filled with water. In the upper part there is a coil pipe for heating the gas. The surface of the gas coil pipe is usually large due to relatively low coefficients of heat transfer. The gas burner of the injection type with a 
long flame makes it possible to use the full volume of the firebox due to the radiation of the flame, which is more than $60 \%$ of the general thermal power. In addition, with full immersion of the combustion chamber in water there is no need for heat-resistant materials or isolation of its fire-resistant shell. Quality of heat generated from the smoke is limited due to the short length of the flue; the efficiency of these heaters reaches $75 \%$. The temperature of the water in the heater can be adjusted through the valves on the fuel supply line, controlled by thermostatic regulators. Fire heaters are especially useful when the gas distribution station lacks electricity.

Electric heaters are used in the presence of the power supply system of the gas distributing station. They are simple, small-sized devices. Often these heaters are structurally combined with a mesh filter, which makes the heating and cleaning equipment compact and inexpensive. Adjusting the heater is very simple. If the temperature increases, thermostat automatically will switch off the electric resistances. Electric heaters are used at low thermal power (until $9 \mathrm{~kW}$ ) because it has of high operating costs.

With local heating, the gas pressure regulator body is placed in a metal shell, which is filled with the heat-transfer fluid. The heat-transfer fluid comes from the heating system of the gas distributing station. By heating the regulator body, the temperature of its walls becomes higher than the temperature of the dew point of the water vapor, so the hydrates inside the gas pressure regulator are not formed. After gas pressure regulator the hydrates are not formed, because as a result of the expansion of gas during the throttling, the dew point of the water vapor in the gas decreases and became lower than the temperature of natural gas.

The main disadvantage of these methods of heating natural gas in front of the gas pressure regulator is the use of additional energy for heating the heat-transfer fluid, which subsequently comes for general heating natural gas or either directly for heating of gas regulator body. Preferably, the source of energy for heating the heat-transfer fluid in the heaters is natural gas.

To reduce production and technological losses for heating natural gas before throttling at gas distribution stations, it is expedient to use a vortex tube [11]. Simplified schematic of the gas-distributive installations with vortex tube on the technological line is shown in Fig. 1.

The vortex tube works as follows. The compressed gas is fed through a tangential nozzle duct into a pipe where intense circular motion is established. In this case, there is an uneven field of temperature. The gas layers near the axis are colder than the inlet gas, and the peripheral layers of the swirled flow are heated. Part of the gas in the form of a cold stream is drawn through the diaphragm, and the other part in the form of heated gas is drawn through the throttle valve on the other side of the pipe. Quantities of heated and cooled gas flows and also its temperatures can be changed by adjusting the amount of heated flow through the throttle valve, [12].

The main indicator characterizing the operation of a vortex tube in the heating mode is the degree of heating, which is equal to the difference between the temperatures of the heated stream $t_{h}$ and the entering stream, $t_{\text {ent }}$ :

$$
\Delta t_{h}=t_{h}-t_{\text {ent }} .
$$




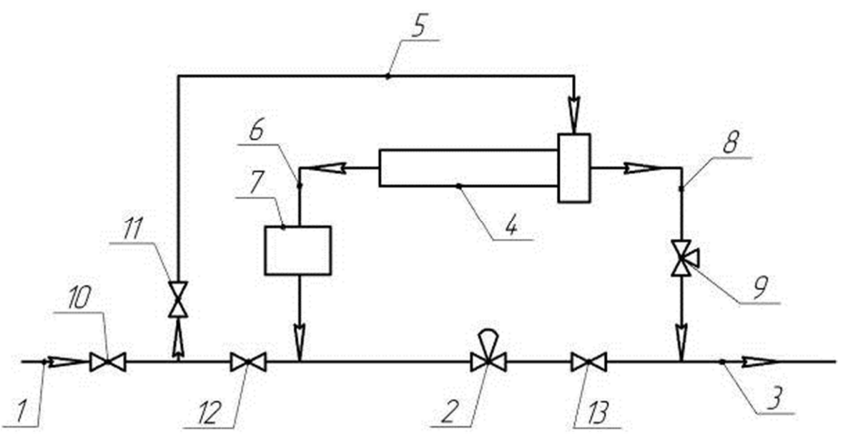

Fig. 1. The technological line of the gas-distributive installations with vortex tube 1 - the main gas pipeline; 2 - gas pressure controller; 3 - distribution gas pipeline; 4 - vortex tube; 5 - pipeline of input gas stream; 6 - pipeline of heat gas stream; 7 - separator; 8 - pipeline of cold gas stream; 9 - protective stop-valve; 10,11,12,13 - taps

The use of a vortex tube for heating natural gas at gas distribution stations before the process of throttling allows its small size and mass, the simplicity of the design, and, most importantly, the lack of an energy source for its operation.

\section{Experimental studies}

The characteristics of the vortex tube are influenced by many factors:

1) geometric characteristics: diameter of the aperture of the diaphragm is $d_{d}[\mathrm{~m}]$; length of the tube of energy separation $l_{t}[\mathrm{~m}]$; geometry of the tube of energy separation (cylindrical, conical); cross-sectional area of the nozzle $f_{n}\left[\mathrm{~m}^{2}\right]$; diameter of the tube of energy separation $d_{t}[\mathrm{~m}]$;

2) thermodynamic parameters: the temperature of the compressed gas entering the pipe $t_{\text {ent }}\left[{ }^{\circ} \mathrm{C}\right]$; the pressure of the compressed gas entering the pipe $p_{\text {ent }}[\mathrm{Pa}]$; pressure of the heated stream $p_{h}[\mathrm{~Pa}]$; fraction of heated stream $\varepsilon$, physical properties of gas (adiabatic indicator $k$ ); heat removal from the walls of the energy separation tube of the vortex tube.

The main task of experimental studies is to determine the optimal geometric sizes of the vortex tube, which provides the maximum degree of heating of the gas (1):

The cross-sectional area of the nozzle depends on the thermodynamic parameters of the vortex tube and is determined by the formula:

$$
f_{n}=\frac{G_{\text {ent }} \cdot a}{k \cdot p_{c r} \cdot p_{\text {ent }}}
$$

where $G_{\text {ent }}$ is the maximum natural gas consumption at the existing gas distribution station $[\mathrm{kg} / \mathrm{s}] ; a$ is the critical flow velocity; $k$ is the adiabatic indicator; $p_{c r}$ is the 
relative pressure at critical speed; $p_{\text {ent }}$ is the pressure at the entrance to the gas distribution station.

In experimental studies geometric sizes were presented in dimensionless form: relative area equal to the ratio of the diaphragm area to the cross-sectional area of the nozzle $\bar{f}=f_{d} / f_{n}$; relative length, which is equal to the ratio of the length of the tube of energy separation to its diameter $\bar{l}=l_{t} / d_{t}$. The fraction of the heated stream, which is equal to the ratio of the amount of heated stream to the amount of the entering stream, was defined as $\varepsilon=G_{h} / G_{\text {ent }}$.

To study the influence of the geometric dimensions of the energy separator on its degree of heating, four diaphragms with a relative area were investigated $\bar{f}=0.5$; $\bar{f}=0.8 ; \bar{f}=1.1 ; \bar{f}=1.7$ and three chambers of energy separation with a relative length $\bar{l}=10, \bar{l}=20, \bar{l}=30$.

Experimental studies were conducted with work agent - the compressed air. Scheme of the experimental installation is shown in Fig. 2.

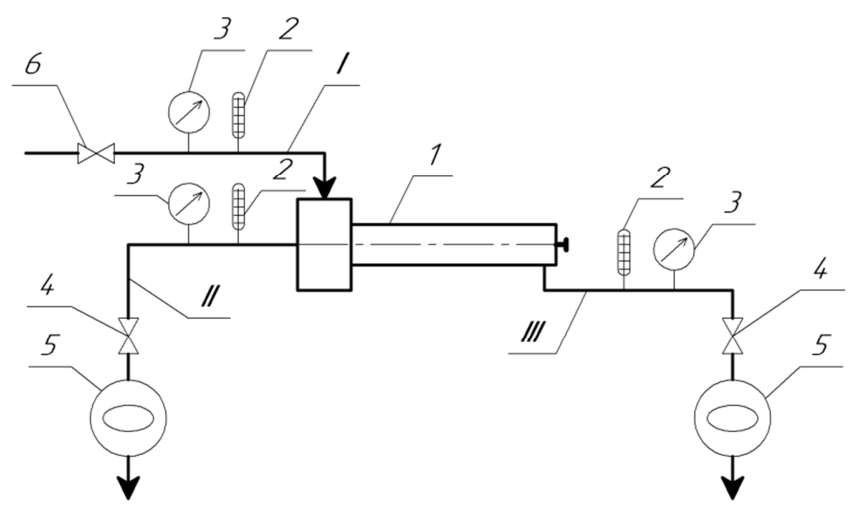

Fig. 2. Scheme of an experimental setup to determine the optimal dimensions of a vortex tube

I - compressed air; II - cooled stream; III - heated stream; 1 - vortex tube; 2 - thermometer;

3 - pressure gauge; 4 - tap; 5 - flow meter; 6 - valve on the inlet air duct

The installation consists of a vortex pipe 1 and air lines according to the inlet compressed air, the output of heated and cooled streams. On each air duct, a crane 4, a pressure gauge 3 with a scale of $0-1 \mathrm{MPa}$, a thermometer 2 with a scale of $0-100^{\circ} \mathrm{C}$, and a differential pressure gauge 5 were mounted. The air to the vortex tube was given by the opening of the valve 6 . Pressure after the vortex tube was created with the help of taps 4 , and also by changing the position of the valve. Preliminary values of thermometers, pressure gauges, flow meters were checked by reference devices. The gas flows were reduced to normal conditions.

Experimental studies were conducted as follows.

The input tangential nozzle of the studied vortex tube was connected by a flexible rubber sleeve with a compressor. The supply of compressed air from the compressor to 
the entrance to the vortex tube was carried out by opening the valve on the inlet air duct. In this case, the steady input air pressure at the inlet to the vortex tube $p_{\text {ent }}$ was set.

After the rectangular air nozzle, the air enters the energy separation chamber, where it was divided into two streams. The cold flow with temperature $t_{c}$ goes out the diaphragm with a diameter $d_{d}$, and the heated stream with the temperature $t_{h}$ goes out through the valve. The constant value of the pressures of heated and cold streams is provided by taps, which are installed on the corresponding air ducts.

At first, the vortex tube valve was installed in position that the fraction of the heated stream was $\varepsilon=0.9$. The streams of cold and heated air went out into the atmosphere. The position of the valve did not change for 5 minutes, so that the motion in the vortex tube became steady. Then, values of manometers, thermometers, and flow meters on the corresponding air ducts were recorded. After that the valve was installed in a new position, reducing the area of the passage of the heated air flow. A new mode of operation of the vortex tube was established. During 5 minutes the mode was maintained, and then the recording of the studied parameters were carried out. The process of changing the mode of operation of the vortex tube was finished when equality was become $\varepsilon=0.1$. Thus, the characteristics of the vortex tube of certain geometric sizes were removed at a certain value of the air pressure at the inlet to the vortex tube in the range $\varepsilon=0.1-0.9$. Then the diaphragm was changed, the energy separation tube was changed and the tests were repeated according to the same scheme.

Fig. 3 - Fig. 7 show the values of the degree of air heating; $\Delta t_{h}$ depends on the relative area $\bar{f}$ and relative length $\bar{l}$ at different values of the fraction of the heated stream $\varepsilon$. Experimental studies were approximated using polynomial of the second degree by Excel program. In Fig. 3 - Fig. 7 the trend lines are plotted.
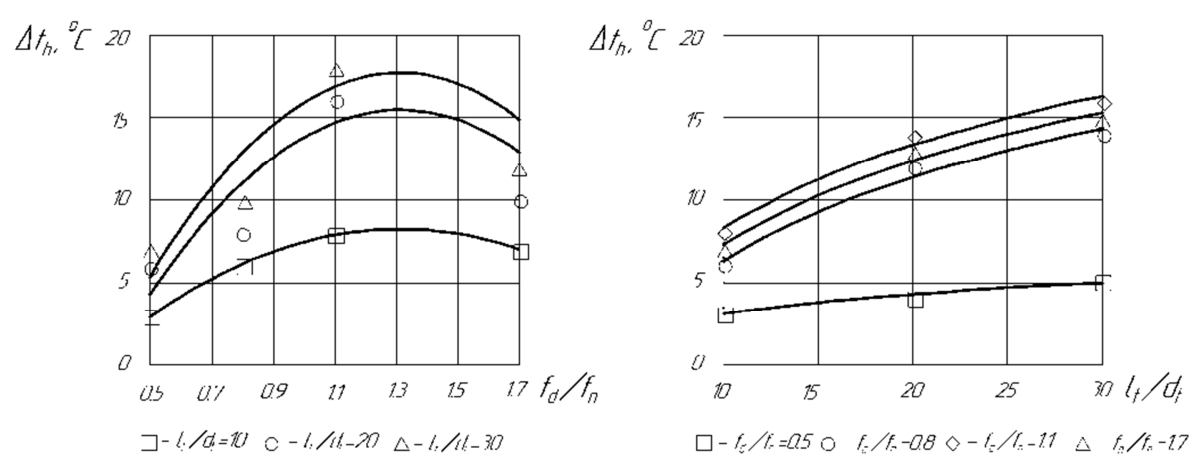

Fig. 3. Values of the degree of air heating depending on relative area and relative length with the fraction of heated stream $\varepsilon=0.1$

As it can be seen in Fig. 3 - Fig. 7, the maximum degree of air heating $\Delta t_{h}$ was achieved at $\bar{f}=1.1$. In addition, Fig. 3 - Fig. 7 show that with an increase of $10<\bar{l}<20$, 
the degree of heating of air increases significantly, and with further increase to $\bar{l}=30$, $\Delta t_{h}$ remains almost unchanged.
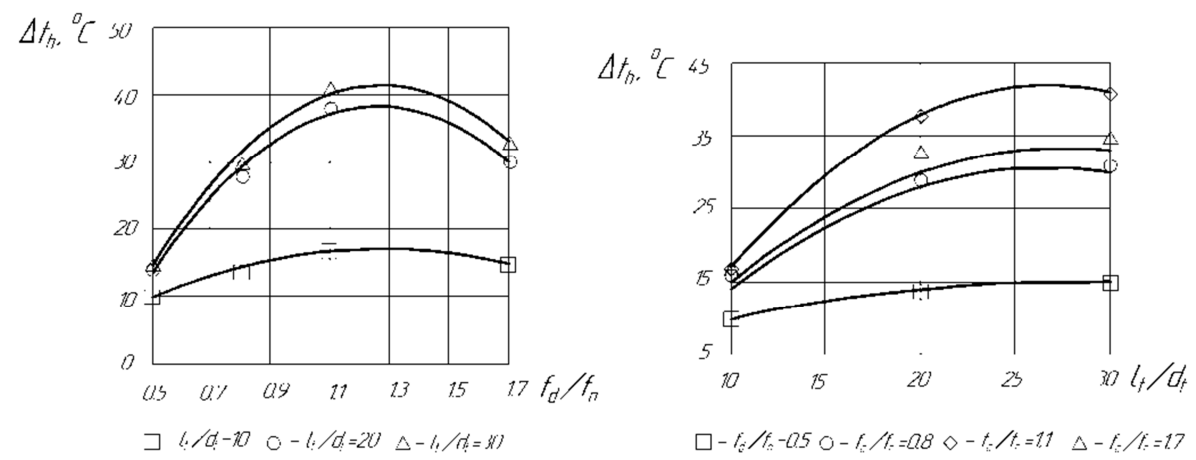

Fig. 4. Values of the degree of air heating depending on relative area and relative length with the fraction of heated stream $\varepsilon=0.3$
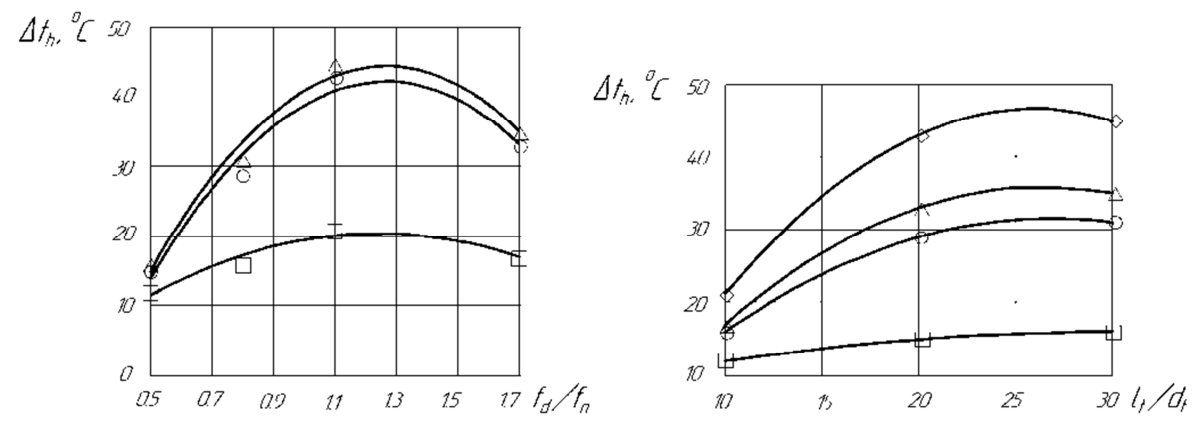

$\square-l: 1 d-10 \quad 0-1: / n=2 i) \quad \Delta-1: 1 t-30$

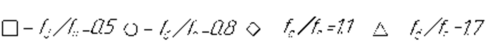

Fig. 5. Values of the degree of air heating depending on relative area and relative length with the fraction of heated stream $\varepsilon=0.5$

If the length of the energy separation tube is greater than its optimal length $l>l_{\text {opt }}$, the change in the separation effect with the increase in the length of the vortex tube is very small. After mathematical processing of graphic dependencies, Fig. 3 - Fig. 7 for the optimal geometric dimensions $\bar{f}=1.27, \bar{l}=20$ were determined.

The geometric dimensions of the vortex tube depend on the amount of natural gas passing through it. Therefore, it is expedient to use it at automated gas distribution stations of the AGDS 1/3, AGDS-3 or block GDSs with the productivity until to $2500 \mathrm{~m}^{3} /$ hour.

For these gas distribution stations, PG-4 or PGA-5 heaters are used, which have an hourly fuel consumption of $3 \mathrm{~m}^{3} /$ hour and $4.2 \mathrm{~m}^{3} /$ hour, respectively. Given that the heating period for Lviv is 191 days, then the quantity of natural gas that heaters will use is: 
$3 \cdot 191 \cdot 24=13752 \mathrm{~m}^{3} /$ year,

$4.2 \cdot 191 \cdot 24=19253 \mathrm{~m}^{3} /$ year .

On average, one gas distribution station can save natural gas as

$(13752+19253) / 2=16502 \mathrm{~m} 3 /$ year.

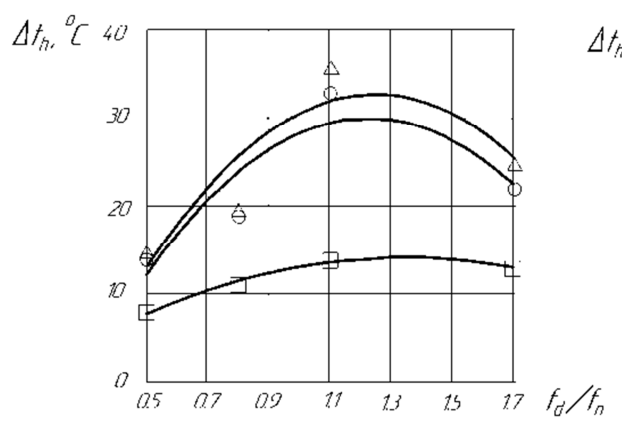

$\square \ll / d=10 \quad 0-4 / d t=20 \Delta-4 / t i-30$

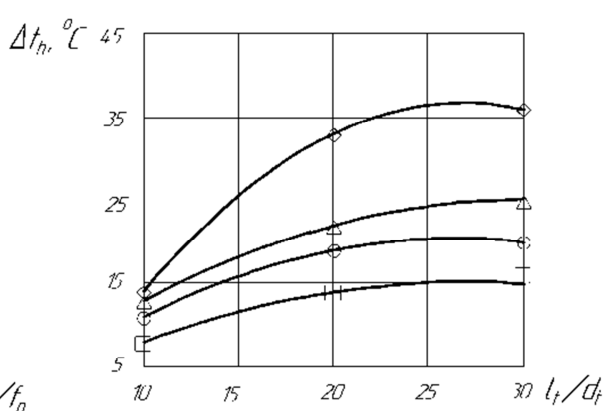

$\sqsubset f_{0} / t_{-}-0.50-f_{0} / f_{-}-a .8 \diamond-f_{2} / f_{n}=17 \Delta-f_{c} / f_{-}-1.7$

Fig. 6. Values of the degree of air heating depending on relative area and relative length with the fraction of heated stream $\varepsilon=0.7$
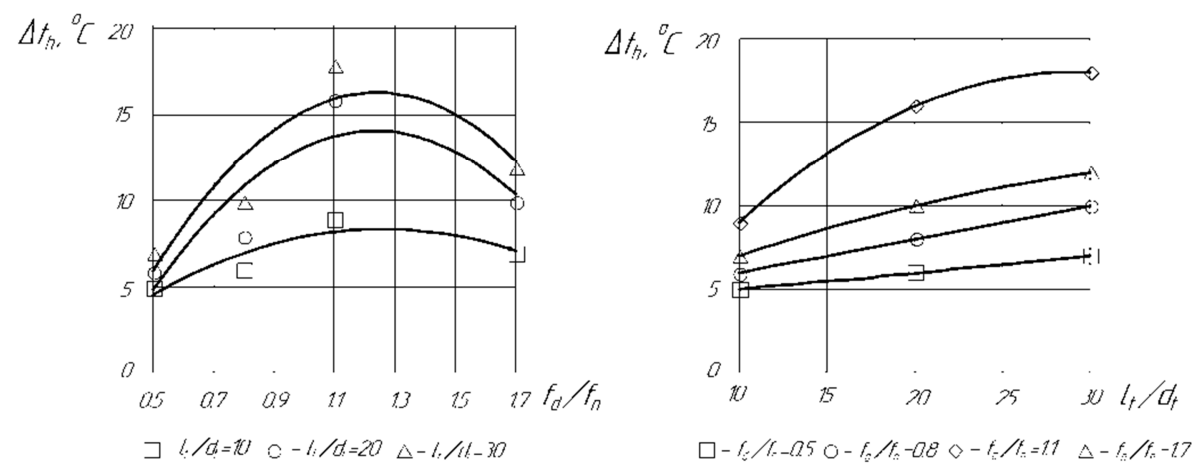

Fig. 7. Values of the degree of air heating depending on relative area and relative length with the fraction of heated stream $\varepsilon=0.9$

Lvivtransgaz operates 213 gas distribution stations [13] and Ukrtransgas operates 1455 gas distribution stations [10]. 1/3 of the gas distribution stations operated by Lvivtransgas have a productivity of up to $2500 \mathrm{~m}^{3} /$ hour, and therefore they can use the vortex tube for heating natural gas before the throttling process.

If all these gas distribution stations will use vortex tubes, then the production and technological losses of natural gas will decrease by: 


$$
16502 \mathrm{~m}^{3} / \text { year } \cdot 71=1171642 \mathrm{~m}^{3} / \text { year, }
$$

which is $1.0 \%$ of the total production and technological losses of gas at Ukrtransgas enterprises.

\section{Conclusion}

As a result of the conducted studies, the optimal sizes of the vortex pipe for its operation at the gas distribution stations for heating the natural gas before the throttling process were determined. It was established that the use of a vortex tubes at gas distribution stations of Lvivtransgaz to prevent the formation of gas hydrates in the pressure regulator can reduce the production and technological losses by $1.0 \%$.

\section{References}

[1] Strakova Z., Takacs J. Indoor air quality and mechanical ventilation for technology buildings Pollack Periodica, Vol. 12, No. 2, 2017, pp. 141-150.

[2] Voznyak O., Sukholova I. Methods of reduction of energy consumption, (in Ukrainian) Rynok instalyaciy, Lviv, Ukraine, No. 495, 2004, pp. 47-51.

[3] Kővári G., Kistelegdi I. Jr. Optimized building automation and control for the improvement of energy efficiency and climate comfort of office buildings, Pollack Periodica, Vol. 10, No. 1, 2015, pp. 71-82

[4] Zhelykh V, Furdas Yu. Biogas technologies: theory and practice, (in Ukrainian) Monograph, Lviv, Ukraine, 2015.

[5] Order of the Ministry of Fuel and Energy of Ukraine, No. 264 dated May 30, 2003, On approving methods for determining specific losses and production and technological costs of natural gas during its transportation by gas distribution networks, (in Ukrainian).

[6] Maric I. The Joule-Thomson effect in natural gas flow-rate measurements, Flow Measurement and Instrumentations, Vol. 16, No. 6, 2005, pp. 387-395.

[7] Beshentseva S. Analysis of methods for preventing hydrate formation in pipelines, (in Russian) Vestnik kibernetiki, No. 11, 2012, pp. 40-44.

[8] Samimi A. Preventing hydrate formation in gas transporting pipe lines with synthetic inhibitors, International Journal of Science and Engineering Investigations, Vol. 1, No. 9, 2012, pp. 48-50.

[9] Behnam R., Ehsan J., Maryam K. Studying and simulating gas hydrate formation procedure in Kamyaran CGS pressure reduction station, International Journal of Advanced Biotechnology and Research, Vol. 7, Special No. 5, 2016, pp. 1030-1036.

[10] Rudnik A., Kolomeyev V., Rozonyuk V., Grigil M., Molokan O., Gerasymenko Yu. Operation and maintenance of gas distribution stations of main gas pipelines: reference, (in Ukainian) Publishing House: 'Rostok', Kiev, Ukraine, 2003.

[11] Patent of Ukraine for invention, No. 43673, Gas distribution station, Koval R., Banakhevych Yu., Balinsky I., Kashina O. (in Ukrainian) 17 December 2001, No. 11.

[12] Smith E. A., Pongjet P. Review of Ranque-Hilsch effects in vortex tubes, Renewable and Sustainable Energy Reviews, Vol. 12, No. 7, 2008, pp. 1822-1842.

[13] Savula S. Management of main gas pipelines 'Lvivtransgaz' - the cradle of the gas industry of Ukraine, (in Ukrainian) Truboprovidnyy transport, Kiev, Ukraine, Vol. 77, No. 5, 2012, pp. 8-13. 